\title{
Representações Sociais de Beleza e de Saúde entre Mulheres com Obesidade
}

Social Representations of Beauty and Health among Obese Women

Representaciones sociales de belleza y salud entre mujeres obesas

Lorena Santos Pinto

Universidade Tuiuti do Paraná, santosp.lorena@gmail.com http://orcid.org/0000-0002-1862-

9881

Gislei Mocelin Polli

Universidade Tuiuti do Paraná, http://orcid.org/0000-0001-7254-7441

Bruna Carolin Basso

Universidade Tuiuti do Paraná, http://orcid.org/0000-0002-9839-0945

Caroline Ferreira da Costa Rezende

Universidade Tuiuti do Paraná, http://orcid.org/0000-0001-5706-3377

Gessica Pereira Neves da Silva

Universidade Tuiuti do Paraná, http://orcid.org/0000-0001-8749-4557

Leticia Lacerda de Almeida

Universidade Tuiuti do Paraná, http://orcid.org/0000-0001-8489-5953

Maria Cristina Antunes

Universidade Tuiuti do Paraná, http://orcid.org/0000-0002-6767-518X 


\title{
Resumo
}

O objetivo deste estudo foi identificar as Representações Sociais (RS) de beleza e de saúde em um grupo de mulheres obesas que queriam emagrecer. Participaram desta pesquisa 15 mulheres maiores de 18 anos, com obesidade. Foi utilizada uma amostragem de conveniência, utilizandose abordagem aleatória em uma Universidade particular de Curitiba e também se utilizando a técnica de "Bola de neve". Foram realizadas entrevistas semiestruturadas sobre as Representações Sociais de beleza e de saúde e as práticas de controle de peso adotadas e questionários autoaplicáveis para caracterização das participantes. Para análise dos dados foi utilizada a Análise Temática Categorial. Observou-se que a mídias têm influência sobre o desejo de emagrecer e sobre as práticas adotadas para perder peso, assim como as RS de beleza tem associação com a magreza e com os cuidados estéticos. A principal influência para a busca do emagrecimento é o meio social e as relações sociais, seja com seus parceiros, família ou amigos. As RS das participantes em relação à saúde e a beleza se relacionam constantemente, gerando práticas sociais.

Palavras-chave: representações sociais, saúde, obesidade, padrão de beleza, mulheres.

\begin{abstract}
This study aimed to identify the social representations (RS) of beauty and health in a group of obese women who want to lose weight. Fifteen women over 18 years of age, with obesity, participated in this study. A convenience sampling was performed using a random approach at a private university in Curitiba and also using a "Snowball" technique. Semi-structured interviews were carried out about the Social Representations of beauty and health and the weight loss practices adopted and self-administered questionnaires were used to characterize the participants. For the analysis of the data the Categorical Thematic Analysis was used. It was observed that the media have influence on the desire to lose weight and on the practices adopted to lose weight, just as the RS of beauty has an association with leanness and aesthetic care. The main influence on the search for weight loss is the social environment and social relations, be it with their partners, family or friends, and the RS of the participants in relation to health and beauty are constantly related, generating representational behaviors.
\end{abstract}

Key words: social representations, health, obesity, beauty pattern, women.

\section{Resumen}

Este estudio se tuvo como objetivo identificar las Representaciones Sociales (RS) de belleza y de salud en las mujeres obesas que quieren adelgazar. Participaron de esta investigación 15 mujeres mayores de 18 años, con obesidad. Participaron de esta investigación 15 mujeres mayores de 18 años, con obesidad. Se realizó un muestreo de conveniencia, utilizando un abordaje aleatorio en una universidad privada de Curitiba y también utilizando la técnica de "Bola de nieve". Se realizaron entrevistas semi estructuradas sobre las representaciones sociales de belleza y salud y las prácticas de pérdida de peso adoptadas y cuestionarios auto administrados para caracterizar a los participantes. Para el análisis de datos se utilizó el análisis categorial. Se observó que los medios tienen influencia sobre el deseo de adelgazar y sobre las prácticas adoptadas para perder peso, así como las RS de belleza tienen asociación con la delgadez y con los cuidados estéticos. La principal influencia para la búsqueda del adelgazamiento es el medio social y las relaciones sociales, sea con sus socios, familia o amigos, siendo que las $R S$ de las participantes en relación a la salud y la belleza se relacionan constantemente, generando comportamientos representacionales.

Palabras clave: representaciones sociales, salud, obesidad, patrón de belleza, mujeres. 


\section{Introdução}

Para a Organização Mundial de Saúde (OMS, 1946), “A saúde é um estado de completo bem-estar físico, mental e social, e não consiste apenas na ausência de doença ou de enfermidade". De acordo com Carrapato, Correia e Garcia (2017), a qualidade de vida está relacionada ao conceito de saúde, que corresponde às necessidades fisiológicas, definições objetivas, mas também com definições cujo significado é subjetivo, como o bem-estar, felicidade, realização pessoal e amor, que para cada pessoa tem uma determinada definição e significado.

A obesidade é considerada uma epidemia global, caracterizada pelo excesso de gordura corporal e pode levar a enfermidades limitantes ou fatais. Mais de 1,9 bilhões de adultos com mais de 18 anos tinham excesso de peso em 2016, destes, 650 milhões eram obesos A obesidade é uma doença crônica que envolve fatores sociais, comportamentais, ambientais, culturais, psicológicos, metabólicos e genéticos. Caracterizada pelo acúmulo de gordura corporal resultante do desequilíbrio energético prolongado, a obesidade pode possuir inúmeras causas, e por isso é considerada complexa (WHO, 2017). Pode ser considerada um dos problemas de saúde mais impactantes mundialmente, sendo uma doença epidêmica, crônica, multifatorial, dispendiosa, de alto risco e que afeta milhões de pessoas, sem determinar idade, sexo, raça, condição financeira (Souza, et al., 2005). A obesidade causa inúmeros prejuízos para a saúde, entre eles :dificuldades respiratórias, problemas dermatológicos, distúrbios do aparelho locomotor, dislipidemias, doenças cardiovasculares, diabetes mellitus e certos tipos de câncer (Guimarães Júnior, Fraga, Araújo \& Tenório, 2018).

A obesidade cresceu $60 \%$ nos últimos dez anos no Brasil, indicando que um em cada cinco brasileiros está acima do peso. O índice de brasileiros obesos passou de 11,8\% a 18,9\% nos anos de 2006 a 2016, de acordo com a pesquisa realizada pela Vigitel (Pesquisa de Vigilância de Fatores de Risco e Proteção para Doenças Crônicas por Inquérito Telefônico). Este aumento colabora com o surgimento de mais casos de diabetes e hipertensão, doenças que pioram a qualidade de vida e podem ser fatais (Brasil, 2017).

A avaliação da obesidade pode ser realizada de diversas formas, uma delas é pelo cálculo do Índice de Massa Corporal (IMC), foma mais utilizada, o perímetro abdominal, a relação cintura-quadril e a presença de dobras cutâneas são outras formas de identificar 
e classificar a obesidade (Moraes, Almeida, \& Souza, 2013). O Índice da Massa Corporal, IMC, é calculado pela divisão do peso em quilograma $(\mathrm{kg})$ pela altura em metros elevada ao quadrado, $\mathrm{kg} / \mathrm{m}^{2}$, em adultos o diagnóstico de obesidade é feito quando o IMC é igual ou superior a $30 \mathrm{~kg} / \mathrm{m}^{2}$. A obesidade é classificada em três graus: obesidade grau I, com IMC entre 30,0 a 34,9, obesidade grau II, IMC 35,0 a 39,9 e obesidade grau III com IMC acima de 40,0. Essa classificação é baseada em padrões internacionais e foi desenvolvida para pessoas adultas descendentes de europeus, adaptada pela Organização Mundial da Saúde (World Health Organization, 2000).

A obesidade é considerada uma pandemia, em consequência ao seu aumento ao longo dos últimos anos. Entre 1980 e 2013, a proporção de sobrepeso ou obesidade entre adultos aumentou de $28,8 \%$ para $36,9 \%$ entre homens e de $29,8 \%$ para $38,0 \%$ entre mulheres. A obesidade têm crescido em maior número entre as mulheres ( $\mathrm{Ng}$, et al., 2014). A sociedade vê a obesidade como uma situação associada a características negativas, contribuindo para a discriminação, preconceito e aos sentimentos de insatisfação. Estes sentimentos de insatisfação são motivados pela exposição de corpos magros nas divesas mídias (revistas, televisão, redes sociais, etc.) que, nas últimas décadas, tem fixado a compulsão à busca do corpo perfeito, especialmente entre as mulheres (Evangelista \& Baptista, 2017).

Desde cedo as pessoas aprendem a valorizar o corpo e isso gera uma busca pela melhoria da aparência estética, já que grande parte se encontra insatisfeita com o próprio corpo. Essa insatisfação corporal vem ganhando cada vez mais destaque dentro da nossa sociedade e a procura para conseguir o corpo tão sonhado aumenta (Cassimiro \& Costa, 2010).

Atualmente a imagem corporal do indivíduo está relacionada à representação do padrão de beleza estabelecido pela mídia. Alcançar o padrão considerado belo é um dos muitos meios pelos quais as pessoas buscam atrair a atenção desejada. Como consequência desse desejo, o número de cirurgias estéticas e transtornos alimentares aumentam (Polli, et al., 2018).

Dessa maneira de pensar e ser, o corpo começou a integrar o indivíduo a um grupo e ao meio social. Ter um corpo no padrão aceito, com curvas, sem gordura, flacidez, representa domínio do seu corpo e destino, assim, a gordura corporal passa a ser considerada doença e causa do fracasso pessoal (Campos, Cecílio \& Penaforte, 2016). Os 
significados atribuídos ao corpo e à sua boa forma aparecem como elementos que reforçam a autoestima, um corpo com músculos rígidos indicaria saúde, revelando o poder que a exaltação e exibição do corpo assumiram no mundo contemporâneo (Siqueira \& Faria, 2008).

A maior parte das pessoas deseja seguir e ter um padrão corporal magro, com isso a indústria de beleza e a alimentícia arrecadam milhões com alimentos e produtos que auxiliam no emagrecimento e no ganho de massa magra, medicamentos, shakes, sopas, cremes e outras infinidades de produtos (Vendruscolo, Malina \& Azevedo, 2014). As propagandas, informações e noticiários incentivam o uso de produtos dietéticos e práticas alimentares para emagrecimento, ao mesmo tempo em que incentivam, contraditoriamente, o consumo de lanches tipo Fast-Food, algumas campanhas de marketing tendem a exaltar de forma exagerada alguns padrões físicos como o "perfeito", com o objetivo de chamar a atenção do consumidor (Melo, Farias \& Kovacs, 2017).

As diversas mídias fazem uma pressão social para persuadir as mulheres a almejarem um modelo idealizado de beleza do corpo e passa a falsa ideia de que todas irão conseguir atingir esse objetivo. Observa-se que essa pressão é muito mais forte para as mulheres do que para os homens, já que o discurso sexista normatiza que as meninas, desde pequenas, de que elas devem ter um corpo delicado e magro, diretamente associado à beleza física e ao que será determinador do seu futuro de sucesso nas relações sociais (Almeida, 2013).

A psicologia social pode auxiliar na compreensão das implicações destes fenômenos sobre o pensamento socialmente compartilhado a respeito da obesidade e dos padrões de beleza socialmente construídos. Um dos aportes teóricos que apresenta importantes contribuições para compreensão deste fenômeno social é a Teoria das Representações Sociais (TRS), desenvolvida por Serge Moscovici em 1961 na França. Com o objetivo de estudar problemas sociais a partir dos fenômenos das Representações Sociais (RS), a teoria busca conhecer o modo como um grupo constrói e compartilha saberes, gerando bases para a compreensão de fatores relacionados a diversas práticas sociais adotadas (Polli \& Camargo, 2013; Oliveira \& Werba, 2014).

Segundo Moscovici (1982), RS são aglomerados de significados e concepções e afirmações geradas no dia a dia por meio de intercomunicação, similares aos mitos e crenças, podendo ser entendidas como interpretações atuais do senso comum. $\mathrm{O}$ criador 
da TRS interessou-se pelo poder do conhecimento do senso comum, buscando entender de que forma e por quais razões as pessoas partilham conhecimentos e constroem uma realidade comum, que permite o compartilhamento da realidade social (Polli, 2013).

Para Jodelet (2001), representação social é um conhecimento diferente do científico, elaborado e compartilhado com o objetivo de construir uma realidade comum para um determinado grupo social, caracterizado como um saber ingênuo. A autora ainda acrescenta que embora não seja um conhecimento cientifico, este saber é também um objeto legítimo de estudo, devido a sua importância nas interações sociais e nos processos cognitivos que elucidam os diversos saberes.

As RS, enquanto sistemas de interpretação, norteiam e ordenam as comunicações e as condutas sociais e intervém na propagação e assimilação de conhecimentos, interferindo no desenvolvimento individual e coletivo e contribuindo na definição de identidades pessoais e sociais. Enquanto fenômenos cognitivos, as RS possibilitam a internalização de experiências sociais, modelos de pensamento, condutas e práticas, os quais são socialmente compartilhados por meio da comunicação social (Jodelet, 2001).

Estão intimamente relacionadas as práticas adotadas. Representações e práticas sociais se influenciam mutuamente, de modo que tanto RS influenciam nas práticas adotadas como as práticas influenciam nas RS (Polli \& Camargo, 2013; Rouquette, 1998). Deste modo é importante compreender RS relacionadas à saúde e a beleza no contexto da obesidade, pois este conhecimento pode gerar bases para compreensão das práticas de controle de peso adotadas.

Alguns pesquisadores procuraram estudar o corpo e a obesidade utilizando a perspectiva das RS. Um levantamento bibliográfico (Barbosa \& Silva, 2016) descreve os impactos ocasionados pela mídia, a partir da produção de padrões de beleza, nos hábitos alimentares de mulheres. Os autores afirmam que a mídia usufrui de vários meios para sustentar um padrão de beleza, sendo este retratado como magro e com pouco peso. Outro estudo similar (Araújo, Coutinho, Araújo-Morais, Simeão \& Maciel, 2018) analisa o conhecimento midiático elaborado sobre o preconceito frente à obesidade. Foram investigadas as RS presentes nas notícias acerca do tema, transmitidas pela mídia impressa no Jornal Folha de São Paulo. O estudo demonstrou a supremacia do padrão corporal magro e saudável e a naturalização do preconceito em relação às pessoas obesas, 
ocorrendo mais frequentemente com as mulheres, que acabam buscando ajustar o seu corpo ao padrão considerado ideal.

Em uma pesquisa sobre as RS da gordofobia (Araújo, Coutinho, Alberto, Santos \& Pinto, 2018) foram analisados os comentários de internautas acerca de uma matéria da revista Superinteressante. Os resultados demonstraram o preconceito e discriminação em relação às pessoas obesas, dando ênfase no discurso de que pessoas com excesso de peso devem se adequar ao padrão ideal do corpo.

Em outro estudo (Koelzer, Castro, Bousfield \& Camargo, 2016) foram analisados comentários de internautas sobre uma reportagem online que apresentava fotografias de uma mulher, branca e obesa, realizando atividades diversas. Os 172 comentários analisados indicaram a presença de discursos que assumem a existência de preconceito na sociedade, mas negam o próprio preconceito.

Ainda tratando do corpo, mas com foco na imagem corporal, foi realizado um estudo com 22 universitários com idades entre 18 a 27 anos que teve como objetivo compreender as representações e a percepção da autoimagem. Os resultados demonstraram que os universitários representavam o corpo como um objeto de investimento, que o conquistavam por meio de dietas e de atividades físicas, visando alcançar o padrão de beleza ideal (Miranda, Almeida, Oliveira, Souza \& Abranches, 2017).

Resultados similares foram obtidos por Silva, Santos, Justos, Bousfield e Camargo (2018), que realizaram um estudo acerca das RS do controle de peso entre pessoas com sobrepeso corporal. Participaram 20 indivíduos de ambos os sexos, que associaram o controle do peso às dietas e exercícios físicos, em busca dos padrões socialmente aceitos de beleza.

Em um estudo com 443 universitários de ambos os gêneros, Camargo, Justo e Jodelet, (2010) verificaram que o principal motivo para as mulheres praticarem exercícios foi a associação da saúde com a estética corporal. Em relação às dietas alimentares restritivas, foi constatado que as mulheres são mais adeptas à essa prática.

Foi realizado um estudo sobre as RS da beleza física (Schlösser \& Camargo, 2015a), com 120 indivíduos de ambos os gêneros, metade dos participantes modelos fotográficos e a outra não modelos. A beleza física foi relacionada à sedução, à modificação corporal, à qualidade de vida e à felicidade, tendo sido associada as 
possibilidades de atração em relação aos possíveis parceiros em detrimento de aspectos de autocuidado ou saúde, tanto entre as mulheres, como entre os participantes de gênero masculino.

Outra publicação dos mesmos autores (Schösser \& Camargo, 2015b), trata de aspectos não normativos de beleza nos relacionamentos amorosos. Os resultados sugerem que os participantes consideram a beleza física como atributo central para estabelecimento de relacionamentos amorosos. Os participantes avaliaram que para outras pessoas a beleza possui importância equivalente à atribuída por eles próprios.

Tendo em conta o contexto social e as pressões exercidas sobre as pessoas que estão acima do peso, este estudo pretendeu estudar as relações entre as Representações Sociais de beleza e de saúde e as práticas de controle de peso adotadas por mulheres obesas.

\section{Método}

\section{Participantes:}

As participantes deste estudo foram 15 mulheres com idades entre 19 e 72 anos $(\mathrm{M}=37,33 ; \mathrm{DP}=16,06)$. Todas foram consideradas obesas segundo a classificação do Índice de Massa Corporal (IMC). Os valores de IMC dos participantes variaram entre $32,05 \mathrm{~kg} / \mathrm{m} 2$ e $41,95 \mathrm{~kg} / \mathrm{m} 2(\mathrm{M}=35,00 ; \mathrm{DP}=2,64)$, o valor mínimo recebeu a classificação de obesidade grau I e o máximo, classificação de obesidade grau III ou obesidade mórbida (WHO, 2000).

As participantes foram contatadas através do método "Bola de Neve", que é baseado em uma rede de amizades entre os membros da amostra, isto é, as primeiras entrevistadas indicam novas pessoas com o mesmo perfil para participarem da entrevista (Dewes, 2013). A primeira participante faz parte da rede de contatos das pesquisadoras.

\section{Procedimentos:}

As pesquisadoras fizeram contato telefônico ou por mensagem de texto com as possíveis participantes para explicar a pesquisa e convidá-las a participar. As entrevistas foram realizadas em locais sugeridos pelas participantes e que proporcionassem privacidade. Inicialmente ocorreu a leitura e assinatura do Termo de Consentimento Livre 
e Esclarecido (TCLE). Em seguida foi realizada a entrevista e posteriormente foi aplicado o questionário com perguntas de caracterização. Optou-se por aplicar a entrevista antes do questionário, como forma de evitar que as questões abordadas no questionário influenciassem as RS manifestadas nas entrevistas.

A presente pesquisa foi submetida à apreciação do Comitê de Ética em Pesquisa com Seres Humanos da UTP, autorizada pelo parecer de número 2.658.784.

\section{Instrumentos:}

Para a obtenção dos dados foram utilizadas entrevistas semiestruturadas e questionários autoaplicáveis. O roteiro da entrevista foi composto por questões sobre as representações sociais da beleza e da saúde, questões sobre as fontes de informação e influência sobre padrões de beleza, sobre práticas de controle de peso e sobre as razões para tentativas de perder peso. O questionário apresentou questões de caracterização e questões sobre dieta alimentar e prática de atividades físicas.

\section{Análise dos dados:}

Bardin (2011) explica a análise de conteúdo como uma técnica de investigação que utiliza uma descrição objetiva, sistemática e quantitativa do conteúdo manifesto das comunicações, tendo por finalidade a interpretação das comunicações. A análise de conteúdo deve ser organizada em três etapas cronológicas: 1) a pré-análise; 2) a exploração do material; 3) o tratamento dos resultados, a inferência e a interpretação.

$\mathrm{Na}$ primeira etapa da análise realizou-se a leitura flutuante de todas as transcrições. Assim, permitindo uma organização dos indicadores de possíveis temas, também foi definido o procedimento a ser seguido ao decorrer da pesquisa, que se constituiu em buscar os assuntos explorados em cada entrevista e a semelhança dos temas relatados por cada um dos participantes.

$\mathrm{Na}$ segunda etapa, a fase de explorar o material, ocorreu a codificação, que compreende a escolha das unidades de registro, classificação e categorização (Bardin, 2011). Unidades de registro são os núcleos de significado comuns entre as respostas das participantes. Esta etapa iniciou-se com a primeira entrevista, na qual procurou identificar as primeiras unidades de registros sobre saúde e beleza. Esse mesmo processo ocorreu com as demais entrevistas transcritas, possibilitando identificar unidades de registros com 
características comuns entre a primeira entrevista e as demais. Através de classificação dos elementos por diferenciação e agrupamento, ocorreram aproximações progressivas daquelas que apresentavam coerência (Bardin, 2011). Este processo resultou em 38 de unidades de registro de saúde e 31 unidades de registro de beleza, que posteriormente originou oito subtemas e depois, três categorias referentes à saúde, e sete subtemas, originando três categorias pertinentes à beleza.

Na terceira etapa, os dados foram trabalhados a partir da inferência e interpretação, que segundo Bardin (2011) possibilita transformar os dados brutos em significativos. Por meio da proposição foi possível desenvolver um enunciado geral, explanando sobre as ideias relatadas de forma generalizada.

\section{Resultados}

O item resultados está subdivido em dois subitens. Inicialmente são apresentadas informações sobre o modelo de beleza e as práticas corporais adotadas. O segundo subitem foca na descrição dos conteúdos das representações sociais de beleza e de saúde obtidas por meio da análise temática categorial realizada.

\section{Padrões de Beleza e Práticas Corporais}

Ao serem questionadas sobre tentativas de perda de peso em algum momento de suas vidas, todas as participantes afirmaram que já fizeram tentativas e algumas alegaram ter tentado várias vezes. As razões apontadas para tal busca foram preocupações com a saúde e com a forma física. Além disso mencionaram a influência dos amigos e uma participante falou sobre a pressão para ser bonita.

Quando perguntado se o modelo de beleza mostrado nas mídias como televisão, revistas e internet tem alguma influência na decisão de perder peso, as participantes mais jovens, de idade entre 19 a 24 anos, relataram que a mídia influencia constantemente em suas decisões de perder peso. Duas entrevistadas, com a idade de 40 a 55 anos, afirmaram que a mídia em algum momento já influenciou na decisão de perder peso e que atualmente não interfere mais. Outras cinco negaram a interferência da mídia em suas decisões.

Seis participantes relataram praticar atividades físicas de duas a três vezes por semana, que variavam de caminhada, corrida e ciclismo ao livre à exercícios de 
musculação e aeróbicos em academias. Seis possuíam alguma doença, em destaque apareceram problemas relacionados à tireoide e à hipertensão.

Em relação às práticas de controle de peso, os métodos que obtiveram ênfase foram o controle da alimentação e a prática de atividades físicas. Em seguida, foram relatados o uso de medicamentos e ajuda profissional. No entanto, ao serem indagadas sobre o que pensavam dos possíveis tratamentos para a perda do peso e emagrecimento, foram obtidos dois grupos de respostas: o que mais se ressaltou foram falas de reprovação, com ênfase nas palavras "loucura", "agressivo" e "preocupante"; e falas de aprovação, como "faria" e "válido".

As participantes relataram que o fator que mais as influenciavam a pensarem sobre a beleza era o meio social onde elas estavam inseridas. Outro fator também frequente foi o padrão de beleza e a família. Quando questionadas sobre o que elas pensavam sobre o padrão de beleza, apesar das respostas serem divergentes, o termo "magro" teve destaque entre as outras palavras, mas também chamaram a atenção palavras mais radicais, tais como "fabricada", "escravidão" e "cruel".

\section{Categorias Temáticas}

Inicialmente foram realizadas as primeiras leituras flutuantes das respostas à questão relativa ao que as entrevistadas pensavam sobre a saúde, as quais possibilitaram obter 38 unidades de registro. Assim, por meio da classificação dos elementos por diferenciação e agrupamento, foi possível realizar as aproximações progressivas daquelas que apresentavam coerência, resultando em oito subtemas e, posteriormente, em três categorias: Descrição de saúde, Qualidade de vida e Práticas de exercícios e alimentares; conforme o Quadro 1. 
Quadro 1.

Categorias Temáticas de Saúde

\begin{tabular}{|c|c|c|}
\hline \multicolumn{2}{|l|}{ egor1 } & \\
\hline Unidades de registro & Subtemas & Categorias \\
\hline $\begin{array}{l}\text { Sem dor, sem tensão; Não ter } \\
\text { problema de saúde; Não estar com } \\
\text { medicação controlada; Boa } \\
\text { respiração; A parte fisiologica } \\
\text { dentro das normalidades. (14) }\end{array}$ & Fisiológica & \multirow[b]{2}{*}{ Descrição de saúde } \\
\hline $\begin{array}{l}\text { Estar com a mente limpa, capaz de } \\
\text { raciocinar; Alto astral; Saúde não é } \\
\text { só o corpo; envolve questão mental, } \\
\text { não ter problema psicológico sério } \\
\text { sem acompanhamento; Emoções } \\
\text { em equilíbrio, sem extremos, } \\
\text { estressada demais, depressiva } \\
\text { demais. (6) }\end{array}$ & Emocional e mental & \\
\hline $\begin{array}{l}\text { Não interferir na qualidade de vida, } \\
\text { no sono, no trabalho; Bem estar em } \\
\text { relação ao próprio corpo, sem } \\
\text { desconforto quanto a aparência; } \\
\text { Que o peso não prejudique a } \\
\text { qualidade de vida; Bem estar fisíco } \\
\text { e emocional; Ter qualidade de vida; } \\
\text { Feliz; (10) }\end{array}$ & $\begin{array}{l}\text { Bem estar e } \\
\text { felicidade }\end{array}$ & \multirow{3}{*}{ Qualidade de vida } \\
\hline $\begin{array}{l}\text { Saúde física depende da minha } \\
\text { saúde emocional; Cuidar do físico e } \\
\text { do emocional; Capacidade física e } \\
\text { mental; É um todo, físico, } \\
\text { emocional e mental. (3) }\end{array}$ & $\begin{array}{l}\text { Equilíbrio: mente } \mathrm{x} \\
\text { corpo }\end{array}$ & \\
\hline $\begin{array}{l}\text { Disposição, fazer as tarefas diárias; } \\
\text { Produzir; Trabalhar; Relacionar } \\
\text { com pessoas de forma saudavél; } \\
\text { Conseguir praticar esportes sem } \\
\text { incomodo; Fazer coisas sem } \\
\text { dificuldade. (9) } \\
\end{array}$ & $\begin{array}{c}\text { Disposição, relação } \\
\text { iinterpessoal e } \\
\text { produção }\end{array}$ & \\
\hline $\begin{array}{l}\text { Ter alimentação correta; Comer e } \\
\text { dormir bem; Estresse descontado na } \\
\text { alimentação; Reeducação alimentar } \\
\text { e comportamento. (7) }\end{array}$ & $\begin{array}{l}\text { Cuidado com a } \\
\text { alimentação e dietas }\end{array}$ & \multirow{3}{*}{$\begin{array}{l}\text { Práticas das } \\
\text { participantes }\end{array}$} \\
\hline $\begin{array}{c}\text { Caminhar, sem cansar; Meditação } \\
\text { ajuda na mente e tem bom animo; } \\
\text { Se cuidar; Fazer exercicios; } \\
\text { Aprender a deixar de ser } \\
\text { preguiçosa.(9) }\end{array}$ & Práticas de exercícios & \\
\hline $\begin{array}{l}\text { Não é facil emagrecer; Antes não } \\
\text { me importava com meu peso, agora } \\
\text { me importo; Entro em crise pelas } \\
\text { roupas que não posso usar. }(4)\end{array}$ & $\begin{array}{l}\text { Emagrecer e estar } \\
\text { magra }\end{array}$ & \\
\hline
\end{tabular}

A categoria Descrição de Saúde é formada pela fala das participantes que buscaram descrever a saúde, conceituando e os aspectos que a constituem. São conteúdos adquiridos pelo cotidiano, pela comunicação recorrente com seus pares e/ou por 
influência da mídia. Foi composta pelos seguintes subtemas: Fisiológica, emocional e mental.

Fisiológica: este subtema que trata da descrição de saúde em relação à parte fisiológica foi frequente na fala das entrevistadas, das 15 mulheres, somente uma não o mencionou. No decorrer da entrevista, a maioria das participantes mencionou em algum momento que saúde seria estar com a parte fisiológica "normal". Conforme os relatos: “Ter os seus parâmetros clínicos dentro da normalidade, pressão arterial, não ter uma doença de base". (P5 - 53 anos, obesidade grau II). "Como eu sendo da área da saúde tem números que você segue, um hemograma, índice glicêmico, para saber algo assim, se você está saudável, está naqueles limites de saúde" (P10 - 42 anos, grau de obesidade I).

Emocional e mental: $\mathrm{O}$ tema sobre a saúde emocional e mental foi citado por seis mulheres, apenas uma, ao mencionar saúde mental, falou sobre o aspecto do raciocínio mental e as demais afirmaram que saúde emocional/mental seria não ter problemas mentais tais como depressão e estresse.

Envolve a questão mental, não ter nenhum tipo de problema psicológico sério, sem acompanhamento. A depressão, por exemplo, você saber que tem um sintoma e você ir atrás de ajuda, de apoio psicológico. A minha saúde não está boa, fiquei muito tempo em estresse constante e descontava o estresse no alimento. (P2 - 20 anos, obesidade grau I)

A categoria qualidade de vida é composta por ideias que relacionam à saúde a sentirem-se bem, é formada por três subtemas: bem-estar e felicidade; equilíbrio: mente x corpo; e disposição, relação interpessoal e produção.

Bem-estar e Felicidade: o segundo subtema que mais esteve presente nos relatos trata do bem-estar e da felicidade, se referindo, por exemplo, à boa relação com o próprio corpo. $\mathrm{O}$ bem-estar é referido pelas entrevistadas com o sentido de se sentirem bem. Neste subtema associam saúde com aparência física, o bem-estar surge ligado à imagem corporal. Este subtema esteve presente na fala de dez participantes. Um dos relatos evidenciam essa ideia: "Se olhar no espelho e se sentir bonita, me sentir bem comigo mesma, estou com saúde" (P10 - 42 anos, grau de obesidade I).

Equilíbrio: Mente x Corpo: Este tema trata do equilíbrio entre a saúde mental/emocional e a saúde do corpo/físico, tendo sido relatado por três participantes. 
Constata-se que para essas mulheres, a saúde depende tanto da mente como do corpo e que o ideal para elas seria uma harmonia entre os dois. "Saúde física depende da minha saúde emocional porque se eu estou bem fisicamente o meu emocional fica mais equilibrado e se o emocional está mais equilibrado o meu mental funciona muito melhor" (P6 - 72 anos, obesidade grau II).

Disposição, Relação Interpessoal e Produção: Neste tema a saúde foi relacionada a se sentirem dispostas, relação interpessoal e à produção, citada por nove participantes. Ter uma vida ativa, conseguir produzir e fazer atividades do cotidiano, bem como ter amizades e contato pessoal, são temas que estão vinculados ao conceito de saúde.

Saúde é estar bem, bem-estar, estar em plena atividade, conseguir fazer tudo que você gostaria. Um exemplo de estar bem é sentir- se bem, acordar com disposição, conseguir fazer as coisas durante o dia, sem debilidades, sem dores e disposto. (P4 - 43 anos, grau de obesidade II)

A categoria Práticas das Participantes se refere às práticas adotadas. São mencionadas as ações que de fato ocorrem e as ações que as entrevistadas acreditam que seriam as adequadas. Esta categoria é formada pelos seguintes subtemas: cuidado com a alimentação e dietas; práticas de exercícios; e emagrecer, estar magra.

Cuidado com a Alimentação e Dietas: O subtema está relacionado com as concepções das mulheres em relação à alimentação e às suas práticas alimentares, o qual foi mencionado por sete participantes durante as entrevistas. A maioria das que mencionaram a alimentação apresentaram em suas falas o termo "correta". Um relato exemplifica o conteúdo do subtema: "Não ter nenhum problema de saúde, depressão, ter uma alimentação correta, sem envolver muita gordura, alimentos congelados. Não comer alimentos embutidos, carne de porco, coisas com gordura, frituras, comida na rua, não preparar sua própria comida" (P2 - 20 anos, grau de obesidade I).

Práticas de Exercícios Físicos: Neste tópico estão expostas as ideias acerca da realização dos exercícios físicos e das atividades que, para elas, melhoram a saúde, seja ela física ou mental. Foram mencionadas as práticas físicas em algum momento da entrevista por nove entrevistadas. Um relato ilustra o tema:

Eu comecei a cuidar, voltei para a yoga, que eu sempre pratiquei ao longo da vida e tinha parado por um tempo. Eu voltei a fazer caminhadas, porque eu percebi que essas atividades físicas me proporcionam melhor ânimo. A prática diária da meditação também 
ajuda na questão da mente, de ter melhor ânimo para fazer as coisas. (P4 - 43 anos, grau de obesidade II)

Emagrecer e Estar Magra: Este subtema apresenta questões do emagrecer, da aparência física e da imagem corporal, como também relataram a ideia de que a diminuição do peso é uma prática de saúde. Este subtema apareceu na fala de quatro das 15 participantes. Algumas alocuções retratam o subtema: "Hoje a gente vê um padrão de saúde para a mulher que todo mundo tem que emagrecer e não é fácil emagrecer, eu sei disso porque eu tento" (P5 - 53 anos, obesidade grau II).

Em seguida foram realizadas leituras flutuantes das 15 entrevistas referentes à questão “O que é beleza física para você?”. Foram estabelecidas 31 unidades de registro; por meio da classificação dos elementos por diferenciação e agrupamento foi possível realizar as aproximações progressivas daquelas que apresentavam coerência, resultando em sete subtemas, e posteriormente em três categorias: Padrão de beleza; Beleza física e estética; Fatores internos e a saúde influenciam na beleza física, conforme o Quadro 2.

A categoria Padrão de Beleza é formada pela fala das participantes que afirmaram ou negaram a existência de um padrão de beleza. Desta forma, está categoria possui dois subtemas: padrão socialmente aceito; e não aceitação do padrão de beleza.

Padrão Socialmente Aceito: Este subtema trata da fala das participantes que declararam a existência de um padrão de beleza e/ou afirmaram se importar com ele. Alguns dos relatos que esclarecem esse subtema: "Você não se sente bem, se você não está na beleza imposta que todo mundo acha bonito. Beleza é ter o corpo da televisão, unha da televisão, o cabelo da televisão" (P13 - 19 anos, grau de obesidade III). Hoje em dia tem que ser magra para ser considerada bonita. Não necessariamente tenha que ser, mas como o padrão diz que você tem que ser magra. Principalmente para as mulheres é muito mais difícil" (P14 - 20 anos, grau de obesidade I).

Não Aceitação do Padrão de Beleza: O tema aborda as concepções das participantes que negam um padrão de beleza, como também o relato de algumas que afirmam não seguir nenhum padrão. Esse conteúdo apareceu na fala de sete entrevistadas. A fala de algumas das mulheres exemplifica o conteúdo deste subtema: "Não tem um padrão" (P7 - 23 anos, grau de obesidade I). "Para mim a beleza física não é associada ao padrão de beleza" (P4 - 43 anos, grau de obesidade II). 
Quadro 2.

Categorias Temáticas de Beleza

\begin{tabular}{|c|c|c|}
\hline \multicolumn{2}{|l|}{ s } & \multirow[b]{2}{*}{ Categorias } \\
\hline Unidades de registro & Subtemas & \\
\hline $\begin{array}{c}\text { Estar no padrão; Ser magro; Corpo de } \\
\text { televisão. (7) }\end{array}$ & $\begin{array}{l}\text { Padrão socialmente } \\
\text { aceito }\end{array}$ & \multirow[b]{2}{*}{ Padrão de beleza } \\
\hline $\begin{array}{c}\text { Não existe padrão; Para mim a beleza } \\
\text { física não é associada ao padrão de } \\
\text { beleza. (7) }\end{array}$ & $\begin{array}{l}\text { Não aceitação do } \\
\text { padrão de beleza }\end{array}$ & \\
\hline $\begin{array}{l}\text { Corpo escultural; Físico ideal; Peso } \\
\text { ideal; Ter um equilíbrio; Não ser } \\
\text { muito magro nem muito gordo; Não } \\
\text { ter nada sobrando; Corpo } \\
\text { aparentemente saudável. (8) } \\
\end{array}$ & $\begin{array}{l}\text { Beleza relacionada } \\
\text { ao corpo }\end{array}$ & \multirow{2}{*}{ Beleza física e estética } \\
\hline $\begin{array}{l}\text { Cuidar do cabelo, cuidar da pele; Ter } \\
\text { cabelo bonito e unhas bonitas; Beleza } \\
\text { física está muito relacionada com a } \\
\text { estética. (5) }\end{array}$ & $\begin{array}{c}\text { Beleza relacionada à } \\
\text { estética }\end{array}$ & \\
\hline $\begin{array}{c}\text { Sorriso; Diversidade; Beleza } \\
\text { individual; Vai além do físico; É o } \\
\text { conjunto; Uma coisa que vem de } \\
\text { dentro. (6) }\end{array}$ & $\begin{array}{l}\text { Beleza está além do } \\
\text { físico }\end{array}$ & \multirow{3}{*}{$\begin{array}{l}\text { Fatores internos e a } \\
\text { saúde influenciam na } \\
\text { beleza física }\end{array}$} \\
\hline $\begin{array}{c}\text { Estar com a autoestima elevada; Se eu } \\
\text { estiver de bom humor vou me achar } \\
\text { linda; Estar plena e feliz; Beleza } \\
\text { começa de dentro para fora; Harmonia } \\
\text { com o corpo e espírito; Aceitar o seu } \\
\text { corpo; }(9)\end{array}$ & $\begin{array}{l}\text { Aceitar o próprio } \\
\text { corpo, estar feliz e } \\
\text { com autoestima } \\
\text { influenciam na } \\
\text { beleza }\end{array}$ & \\
\hline $\begin{array}{l}\text { Estar saudável; Estar confortável; } \\
\text { Fazer exames regularmente; Manter a } \\
\text { saúde mental saudável. (3) }\end{array}$ & $\begin{array}{l}\text { Beleza é estar } \\
\text { saudável } \\
\text { fisicamente e } \\
\text { mentalmente }\end{array}$ & \\
\hline
\end{tabular}

A categoria Beleza Física e Estética é formada pela fala das participantes que buscaram descrever a beleza, definindo-a e caracterizando os aspectos que a constitui, seus conteúdos foram obtidos tanto pela comunicação com seus pares como pela influência da mídia. A categoria foi dividida em dois subtemas: beleza relacionada ao corpo e beleza relacionada à estética.

Beleza Relacionada ao Corpo: O subtema agrupa respostas que relacionam a beleza às características físicas corporais. Esse conteúdo foi abordado por oito mulheres. Alguns trechos que exemplificam essa temática: "A beleza física para mim era ter uma corpo escultural porque quando eu era jovem, sempre malhei muito, sempre estive em 
academia e perna torneada, barriga tanquinho, peito erguido, braço, então isso para mim era beleza física" (P1 - 54 anos, grau de obesidade I). "Não ter nada sobrando, fora do lugar, caindo, sacudindo. Não ter dobrinha no pescoço, na barriga, na perna, isso é uma coisa que incomoda bastante. Um corpo aparentemente saudável, sem excesso de gordura" (P2 - 20 anos, grau de obesidade I).

Beleza Relacionada à Estética: Este subtema agrupa fala de cinco participantes que associaram a beleza à aspectos físicos gerais, que vão além da forma física corporal, incluindo pele, cabelo, harmonia facial, entre outros. A seguir alguns relatos que evidenciam essas concepções: “A estética é estar em harmonia, ter um bom cabelo, um bom trato de pele, estar confortável, estar saudável, caminhadas faz parte desse processo, passear, viajar" (P6 - 76 anos, grau de obesidade II). "Então beleza para mim, é muito relacionada a isso, você ter um cabelo, pele boa, estar um pouco mais magra, estar no seu peso adequado" (P12 - 20 anos, grau de obesidade I).

A categoria "Fatores Internos e a Saúde Influenciam na Beleza Física" relaciona diversos fatores que se afastam do padrão classificado nas categorias anteriores. Essa categoria se dissemina em três subtemas: beleza está além do físico: é um conjunto de fatores que define a beleza da pessoa; aceitar o próprio corpo, estar feliz e com autoestima influenciam na beleza; e beleza é estar saudável fisicamente e mentalmente.

Beleza está além do Físico: Nesse subtema as participantes relatam que a beleza advém de aspectos individuais, subjetivos. Seis mulheres apresentaram este tipo de conteúdo. Um relato ilustra este subtema: "Talvez a beleza para mim está mais relacionada a uma coisa que vem de dentro... uma coisa que a pessoa falou, ou um brilho nos olhos ... tá muito mais relacionado com algo que vem de dentro" (P3 - 39 anos, grau de obesidade I).

Aceitar o Próprio Corpo, estar Feliz e com Autoestima Influenciam na Beleza: As entrevistadas estabeleceram relações entre a beleza e a autoaceitação, a felicidade e a autoestima. O subtema que trata desta visão foi mencionado na fala de nove participantes. Conforme os relatos: “As pessoas que se sentem bem com o que elas são, elas se mostram mais bonitas, elas estão mais inteiras, elas gostam do que são e do que fazem. Beleza é associado com felicidade" (P4 - 43 anos, grau de obesidade II). 
Hoje eu já olho de outra forma, a beleza física começa de dentro para fora. Se você não estiver bem, você pode ser magérrima, ter todo o estilo de beleza que o padrão hoje no mundo fala, a mídia fala e não vai adiantar nada. (P1 - 54 anos, grau de obesidade I)

Beleza é estar Saudável Fisicamente e Mentalmente: O tema sobre estar com saúde física e mental foi relacionado com a beleza por três mulheres. Esse subtema se diferencia do anterior pela ênfase dada à saúde física e mental, sem destacar necessariamente a aceitação do próprio corpo e autoestima como condição para tanto. Um relato ilustra o tema: "Para manter minha saúde mental saudável eu gosto de passear, e viajar é o que mais gosto. Estar confortável, estar saudável, caminhadas faz parte desse processo, passear, viajar" (P6 - 76 anos, grau de obesidade II).

\section{Discussão}

Ao partilhar ideias, pensamentos e concepções por meio da comunicação são geradas ou reproduzidas as representações sociais, essas representações são compostas de conteúdos originados das relações sociais (Polli \& Camargo, 2010). Após serem analisados os subtemas, de ambos os objetos foi possível perceber que as RS estão relacionadas às práticas adotadas pelas participantes. Em relação à saúde, formaram-se três categorias, duas referentes às RS e a outra categoria referente às práticas sociais das participantes. As categorias que colaboraram para a formação das RS de saúde foram: Descrição de saúde e Qualidade de vida. A categoria 3 - práticas das participantes contribui para a descrição das práticas de controle de peso.

Para as participantes da pesquisa, saúde remete a um corpo dentro da "normalidade", sem doenças físicas ou problemas psicológicos, tais como depressão e estresse. Além disso, para ser saudável é necessário estar feliz e ter disposição, se alimentar corretamente e praticar atividades físicas, elas apontam que é necessário estar magra e/ou emagrecendo. Dados similares foram obtidos no estudo de Silva, Santos, Justos, Bousfield e Camargo (2018), em que o corpo magro era visto como saudável, retratando a saúde física e a saúde psicológica do sujeito, sugerindo uma boa autoestima e autoimagem.

As representações sociais das participantes sobre a saúde são compatíveis com as práticas realizadas e mencionadas por elas. As práticas citadas indicam a busca pelo que 
consideram saudável, com a realização de atividades físicas, e práticas direcionadas à alimentação, tais como as dietas restritivas e de reeducação alimentar. É possível perceber a relação entre as RS e as práticas sociais por meio das análises realizadas. Rouquette (1998) chama atenção para o caráter bidirecional e complexo existente entre as RS e as práticas sociais.

Quanto à beleza, obtiveram-se três categorias: padrão de beleza; beleza física e estética; fatores internos e a saúde influenciam na beleza física. As RS da beleza, neste estudo, estão relacionadas ao padrão de beleza, ter um corpo e peso ideal, ter pele, unhas e cabelos bonitos e bem cuidados. Além disso é importante estar com autoestima elevada, aceitar o próprio corpo e estar saudável mentalmente e fisicamente. No estudo de Camargo, Goetz, Bousfeild e Justo (2011), foi constatada uma idolatria à beleza física, que recebeu maior relevância do que os cuidados com a saúde, com o equilíbrio emocional e o bem-estar.

As participantes deste estudo relataram que o fator que mais as influencia a pensarem sobre a beleza é o meio social em que elas estão inseridas. Corroboram Schlösser e Camargo (2015a), que relatam que um dos elementos que constitui a beleza física baseia-se nas relações interpessoais. Quando questionadas sobre o que elas pensam sobre o padrão de beleza, apesar de as respostas serem divergentes, o termo "magro" teve destaque entre as outras palavras que chamaram a atenção, tais como: "fabricada", "escravidão" e "cruel". Quando perguntado se o modelo de beleza mostrado nas mídias como televisão, revistas e internet tem alguma influência na decisão de perder peso, a maioria das mulheres participantes relataram que a mídia influencia constantemente e/ou já interferiu em suas decisões de perder peso.

A pesquisa de Barbosa e Silva (2016) constatou que o modelo de beleza transmitido pela mídia permeia a ideia de que para o corpo ser considerado feminino deve ser magro. Em concordância Godoi, Mastella e Uchôa (2018) constataram que as mídias são influenciadoras do padrão e do consumo de beleza; também destacam a procura pela magreza e cuidados com o cabelo são as principais preocupações com relação à beleza; e a cobrança social por beleza por parte dos parceiros, amigas e familiares; ou seja, pelo meio social.

Durante a pesquisa observaram-se relatos ambíguos, principalmente entre as participantes mais velhas, sobre o desejo de emagrecer para a melhora da saúde ou para 
sentirem-se aceitas. Nos momentos em que relataram o desejo de ser magra, a perda de peso estava relacionada à saúde ou para ter uma condição física melhor, mas também para adequarem seu corpo ao padrão socialmente aceito. Aguiar, Camargo e Bousfield (2018) observaram que o desejo de rejuvenescer está relacionado ao padrão de beleza, mas também à busca pela saúde, fator que se torna mais importante com o passar dos anos. Já nas respostas das participantes mais jovens não há a mesma ambiguidade, elas assumiram que por trás da vontade de emagrecer estava a vontade de se adequar a um padrão socialmente aceito de beleza, de possuir um corpo esguio para se sentir bela e psicologicamente bem. Esses resultados indicam o poder das diferentes mídias na formação das representações sociais (Moscovici, 1988). O modelo midiático de beleza para as mulheres mais velhas está intimamente relacionado à manutenção da saúde (Aguiar, Camargo \& Bousfield, 2018). Entre as mulheres mais jovens, este modelo está associado principalmente à magreza (Miranda, et al., 2017; Polli, et al., 2018, Silva et al., 2018).

Os resultados obtidos nesta pesquisa demonstram que as mídias têm influência sobre as práticas de controle de peso e o desejo de emagrecer, assim como as RS de beleza têm associação com a magreza e com os cuidados estéticos (Miranda, et al., 2017; Polli, et al., 2018, Silva et al., 2018), e que a principal influência para a busca do emagrecimento é o meio social e as suas relações sociais, seja com seus parceiros, família ou amigos (Koelzer et al., 2016; Araújo et al., 2018).

As RS das participantes em relação à saúde e a beleza se relacionam constantemente, gerando práticas sociais. Estudos no campo das Representações Sociais procuram compreender as relações entre representações e práticas sociais (Rouquette, 1998; Polli \& Camargo, 2013) e neste estudo foi possível perceber um dos elos de influência. $\mathrm{O}$ discurso propagado por diferentes mídias enfatiza um padrão de beleza que exerce influência nas representações sociais das mulheres que participaram deste estudo. A partir do compartilhamento de saberes, esses discursos são reforçados no cotidiano, fazendo com que os grupos sociais exerçam pressão para adequação a tal modelo. Então as práticas de emagrecimento e controle de peso são adotadas, como forma de adequação ao padrão de beleza socialmente compartilhado (Justo, Camargo \& Bousfield, 2018).

Foi destacada a importância da divulgação da mídia sobre o corpo magro, mas muitas das participantes relataram que a maior cobrança para seguir um padrão vem do 
contexto social que estão inseridas, seja pelos familiares ou por terceiros. A internalização desses padrões de beleza gera uma autocobrança e uma sensação de desconforto com seu próprio corpo. As mulheres adquirem práticas inadequadas para a redução do peso, como dietas restritivas, jejum intermitente, uso de medicamentos termogênicos e inibidores de apetite sem prescrição médica, assim podendo agravar ou ocasionar outros problemas de saúde (Figueiredo, Nascimento \& Rodrigues, 2017, Schösser \& Camargo, 2015a).

\section{Considerações finais}

O objetivo deste estudo foi descrever as representações sociais de mulheres obesas em relação à saúde e ao padrão de beleza, buscando compreender se a busca pelo emagrecimento estaria relacionada à saúde ou a padrões estéticos disseminados pela mídia. Entendemos as dificuldades envolvidas no processo de emagrecimento dessas mulheres, sabendo que as pessoas fora do padrão de beleza magro são vistas com maus olhos, como desleixadas.

É indiscutível que as representações sociais tenham grande significado e influência para a busca do emagrecimento. Vale destacar que há uma grande procura em atingir o padrão estético por mulheres mais jovens e as mais velhas, apesar de desejarem a magreza, demonstram uma vontade maior de se ter saúde. Desta forma, os veículos midiáticos como televisão e revistas deveriam mostrar a diversidade de corpos, pois hoje muito se fala sobre empoderamento feminino, mas ainda não se fala sobre como se empoderar mulheres obesas, não havendo pessoas com quem elas se identifiquem. $O$ corpo gordo ainda é visto como feio e desleixado, assim se destaca ainda mais a importância da representatividade na mídia, assim auxiliando no empoderamento de mulheres com obesidade.

Como resolução deve-se conscientizar que o gordo também é belo, que não há necessidade de ser magro para fazer parte de algo, se sentir incluída e ser dona de si, iniciando-se o empoderamento de mulheres acima do peso. Dessa forma, justifica-se a importância desse estudo, uma vez que, conhecer o que as mulheres obesas pensam e suas representações sociais, nos fornece subsídios para uma reflexão sobre a importância de problematizar padrões de beleza perfeitos e inatingíveis. 
Este estudo traz importantes contribuições para a compreensão da dinâmica entre a mídia, as representações e as práticas sociais, mas é importante considerar que as conclusões foram obtidas a partir de entrevistas realizadas com um número reduzido de participantes. Além disso variáveis pessoais não foram consideradas, além do IMC. Outros estudos poderiam identificar diferenças entre mulheres de estratos sociais, econômicos e educacionais diferenciados, ou ainda considera diferenças étnicas, fatores que não foram contemplados neste estudo e que podem estar relacionados à forma como os padrões de beleza são incorporados. Diante do saber alcançado a partir deste estudo, considera-se urgente aprofundar ainda mais o conhecimento acerca das representações sociais dessa população em relação às suas relações interpessoais e autoimagem.

\section{Referências}

Aguiar, A. d., Camargo, B. V., \& Bousfield, A. B. d. S. (2018). Envelhecimento e Prática de Rejuvenescimento: Estudo de Representações Sociais. Psicologia: Ciência e Profissão, 38(3), 494-506. doi: 10.1590/1982-37030004492017

Almeida, R. J. (2013). Obesidade nos corpos das mulheres e os olhares sobre os discursos medicalizantes. Soc. Estado 28(2), 465-466. doi: 10.1590/S010269922013000200019

Araújo, L., Coutinho, M., Alberto, M., Santos, A., \& Pinto, A. (2018). Discriminação baseada no peso: representações sociais de internautas sobre a gordofobia. Psicologia em estudo, 23, 1-17. doi: 10.4025/psicolestud.v23i0.34502

Araújo, L. S., Coutinho, M. D. P. L., Araújo-Morais, L. C., Simeão, S. D. S. S., \& Maciel, S. C. (2018). Preconceito frente à obesidade: representações sociais veiculadas pela mídia impressa. Arquivos Brasileiros de Psicologia, 70(1), 69-85. Recuperado de: http://pepsic.bvsalud.org/pdf/arbp/v70n1/06.pdf

Barbosa, B. S. N., \& Silva, L. D. V. (2016). A mídia como instrumento modelador de corpos: um estudo sobre gênero, padrões de beleza e hábitos alimentares. Razón y Palabra, 20 (94), 672-687. Recuperado de: https://www.revistarazonypalabra.org/index.php/ryp/article/view/732

Bardin, L. (2011). Análise de conteúdo. Lisboa: Edições 70 
Brasil (2017). Vigitel -Saúde Suplementar: vigilância de fatores de risco e proteção para doenças crônicas por inquérito telefônico [recurso eletrônico]. Ministério da Saúde, Agência Nacional de Saúde Suplementar. Brasília: Ministério da Saúde. Recuperado de:

http://bvsms.saude.gov.br/bvs/publicacoes/vigitel_brasil_2017_saude_suplementar.p $\underline{\mathrm{df}}$

Camargo, B., V., Goetz, E. R., Bousfield, A. B. S., \& Justo, A. M. (2011). Representações sociais do corpo: estética e saúde. Temas em Psicologia, 19(1), 257-268. Recuperado de: https://www.redalyc.org/html/5137/513751437021/

Camargo, B. V., Justo, A. M., \& Jodelet, D. (2010). Normas, representações sociais e práticas corporais. Interamerican Journal of Psychology, 44(3), 449-457. Recuperado de: https://www.redalyc.org/pdf/284/28420658006.pdf

Campos, M. T. A., Cecílio, M. S., \& Penaforte, F. R. (2016). Corpo-vitrine, ser mulher e saúde: produção de sentidos nas capas da Revista Boa Forma. DEMETRA: Alimentação, Nutrição \& Saúde, 11(3), 611-628. doi: 10.12957/demetra.2016.22394

Carrapato, P., Correia, P., \& Garcia, B. (2017). Determinante da saúde no Brasil: a procura da equidade na saúde. Saúde e Sociedade, 26(3), 676-689. doi: 10.1590/s010412902017170304

Cassimiro, E., \& Costa, S. (2010). Padrões sociais com a imagem corporal: a insatisfação das pessoas com o corpo. In $3^{\circ}$ Conceno: o norte da educação física e ciências do esporte. Castanhal e Belém. Recuperado de: http://congressos.cbce.org.br/index.php/3conceno/3conceno/paper/viewFile/3950/22 $\underline{18}$

Dewes, J. O. (2013). Amostragem em Bola de Neve e Respondent-Driven Sampling: uma descrição dos métodos. Porto Alegre:UFRGS

Evangelista, K. C. M., \& Baptista, T. J. R. (2017). Mulher nova, bonita e carinhosa: uma análise de conteúdo da revista Ludovica. Revista Café com Sociologia, 6(2), 263-282. Recuperado de: https://revistacafecomsociologia.com/revista/index.php/revista/article/view/740/pdf 1 
Figueiredo, D. d. C., Nascimento, F. S., \& Rodrigues, M. E. (2017). Discurso, culto ao corpo e identidade: representações do corpo feminino em revistas brasileiras. Linguagem em (Dis)curso, 17(1), 67-88.

Godoi, C. K., Mastella, A. S., \& Uchôa, A. G. F. (2018). Integração metodológica entre grupo de discussão e análise sociológica do discurso: um caso exemplificador sobre o discurso feminino acerca do consumo da beleza. Revista Eletrônica de Administração, 24(1), 30-60. doi: 10.1590/1413-2311.180.69478

Guimarães Júnior, M. S., Fraga, A. S., Araújo, T. B., \& Tenório, M. C. C. (2018) Fator de risco cardiovascular: a obesidade entre crianças e adolescentes nas macrorregiões brasileiras. Revista Brasileira de Obesidade, Nutrição e Emagrecimento, 12(69), 132142. Recuperado de: http://www.rbone.com.br/index.php/rbone/article/view/670/517 Jodelet, D. (2001). Representações sociais: um domínio em expansão. In: D. Jodelet, $A s$ representações sociais, 17-44. Rio de Janeiro: EdUERJ.

Justo, A. M., Camargo, B. V., \& Boulsfield, A. B. (2018). Sobrepeso e controle de peso: pensamento leigo e suas dimensões normativas. Psicologia: Teoria e Prática, 20(20), 213-224. doi: 10.5935/1980-6906/psicologia.v20n2p213-224.

Koelzer, L. P., Castro, A., Bousfield, A., \& Camargo, B. V. (2016). O "olhar preconceituoso": Representações sociais sobre fotografias nas redes sociais. Estudos e Pesquisas em Psicologia, 16(2), 431-449. doi: 10.12957/epp.2016.29169

Melo, F. V. S., de Farias, S. A., \& Kovacs, M. H. (2017). Estereótipos e estigmas de obesos em propagandas com apelos de humor. Organizações \& Sociedade, 24(81), 305-324. doi: $\underline{10.1590 / 1984-9230816}$

Miranda, R. F., Almeida, T. S., Oliveira, T. C., Souza, C. S., \& Abranches, M. V. (2017). Representação corporal entre jovens universitários: beleza, saúde e insatisfação na vivência de um corpo-vitrine. Revista Psicologia, Diversidade e Saúde, 6(4), 258- 269. doi: $\underline{10.17267 / 2317-3394 \text { rpds.v6i4.1696 }}$

Moraes, A. L., Almeida, E. C., \& Souza, L. B. (2013). Percepções de obesos deprimidos sobre os fatores envolvidos na manutenção da sua obesidade: investigação numa unidade do Programa Saúde da Família no município do Rio de Janeiro. Physis: Revista de Saúde Coletiva, 23(2), 553-572. doi: 10.1590/S0103-73312013000200012. Moscovici, S. (1988). Notes towards a description of social representations. European Journal of Social Psychology, 18, 211-250. 
Moscovici, S. (1982). On social representations. In: J. P. Forgas, Social cognition: Perspectives on everyday understanding, 181-209. London: Europen Associention of Experimental Social Psicology.

Ng, M., Fleming, T., Robinson, M., Thomson, B., Graetz, N., Margono, C., \& Abraham, J. P. (2014). Global, regional, and national prevalence of overweight and obesity in children and adults during 1980-2013: a systematic analysis for the Global Burden of Disease Study 2013. The lancet, 384(9945), 766-781. doi: 10.1016/S01406736(14)60460-8

Oliveira, F. D., \& Werba, G. C. (2014). Representações sociais. In: Jacques, M. D. G. C., Strey, M. N., Bernardes, N. M. G., Guareschi, P. A., Carlos, S. A., \& Fonseca, T. M. G. Psicologia social contemporânea: livro-texto, 104-115. Petrópolis: Vozes.

Organização Mundial de Saúde (OMS). Constitution of the World Health organization. Basic Documents. $1946 . \quad$ Recuperado de: http://www.direitoshumanos.usp.br/index.php/OMS-Organiza\%C3\%A7\%C3\%A3oMundial-da-Sa\%C3\%BAde/constituicao-da-organizacao-mundial-da-saudeomswho.html

Polli, G. M., \& Camargo, B. V. (2010). A teoria das representações sociais e a abordagem estrutural. In: J. M. Segata, Psicologia: Inovações, 13-41. Rio do Sul: Editora Unidavi.

Polli, G. M. (2013). Representações sociais do meio ambiente e da água na mudança de paradigmas ambientais. (Doutorado), Universidade Federal de Santa Catarina, Florianópolis.

Polli, G. M., \& Camargo, B. V. (2013). Meio ambiente e água sob a perspectiva da teoria das representações sociais. Psicologia: Ciência e Profissão, 33(2), 255-271. doi: 10.1590/S1414-98932013000200002

Polli, G. M., Silva, J. C. C., Pereira, M. G., Reis, R. A., Peruci, T. T., Gelinski, E. M. M., \& Gebara, T. S. S. (2018). Social representations of anorexia among university students and risk factors: possible relations. Psico PUCRS, 49(1), 12-20. doi: $\underline{10.15448 / 1980-8623.2018 .1 .25251}$

Rouquette, M. L. (1998). Representações e Práticas Sociais: Alguns elementos teóricos. In A. S. P. Moreira \& D. C. Oliveira (Eds.), Estudos interdisciplinares de representação social (pp. 39-46). Goiânia: AB 
Schlösser, A., \& Camargo, B. V. (2015a). Representações sociais da beleza física para modelos fotográficos e não modelos. Psico PUCRS, 46(2), 274-282. doi: $10.15448 / 1980-8623.2015 .2 .17725$

Schlösser, A., \& Camargo, B. V. (2015b). Aspectos não explícitos das representações sociais da beleza física em relacionamentos amorosos. Psicologia e Saber Social, 4(1), 89- 107. doi: 10.12957/psi.saber.soc.2015.10405

Silva, D. S., Santos, M. B., Justo, A. M., Bousfield, A. B. S., \& Camargo, B. V. (2018). Representações Sociais Relativas ao Controle de Peso Corporal para Pessoas com Sobrepeso. PSI UNISC, 2(2), 66-77. doi: 10.17058/psiunisc.v2i2.11703

Siqueira, D., \& Faria, A. (2008). Corpo, saúde e beleza: representações sociais nas revistas femininas. Comunicação Mídia e Consumo, 3(9), 171-188. doi: $\underline{10.18568 / \mathrm{cmc} . v 3 i 9.95}$

Souza, J. M. B. D., Castro, M. M. D., Maia, E. M. C., Ribeiro, A. N., Almondes, K. M. D., \& Silva, N. G. D. (2005). Obesidade e tratamento: desafio comportamental e social. Revista Brasileira de Terapias Cognitivas, 1(1), 59-67. doi: 10.5935/1808$\underline{5687.20050007}$

Vendruscolo, M. F., Malina, A., \& de Azevedo, Â. C. B. (2014). A concepção de obesidade e padrão corporal por mediações ideológicas da mídia. Pensar a Prática, 17(2). doi: 10.5216/rpp.v17i2.26563

World Health Organization (2000). Obesity: preventing and managing the global epidemic. (WHO Technical Report Series, 894). Geneva: World Health Organization. World Health Organization (2017). Factsheet: Obesity and overweight. Disponível em: http://www.who.int/mediacentre/factsheets/fs311/en/

Submetido: 16/01/2020

Aprovado: 28/04/2020 